\title{
Clinical Hypnosis \& VR, Subconscious Restructuring- Brain Rewiring \& the Entanglement with the 8 Pillars of Metacognition X 8 Layers of Consciousness X 8 Intelligences
}

\author{
https://doi.org/10.3991/ijoe.v18i01.26859 \\ Athanasios Drigas $^{1(\varpi)}$, Eleni Mitsea ${ }^{1,2}$, Charalampos Skianis ${ }^{2}$ \\ ${ }^{1}$ Net Media Lab-Mind \& Brain R\&D, Institute of Informatics and Telecommunications \\ N.C.S.R. 'Demokritos', Athens, Greece \\ ${ }^{2}$ Department of Information and Communication Systems Engineering, University of the \\ Aegean, Samos, Greece \\ dr@iit.demokritos.gr
}

\begin{abstract}
Thomas Edison, Albert Einstein, Nikola Tesla, Aldous Huxley, Sergei Rachmanicoff, Chopin, Goethe. What do these people have in common? They all used hypnosis to explore and expand the boundaries of their intelligence. The aim of the current review is to investigate the impact of clinical hypnosis on Metacognition, Consciousness and Intelligence based on the counterpart model. Furthermore, we examine the role of virtual reality hypnosis in service of metacognition. The results showed that clinical hypnosis -with the power of attention and imagery- can effectively and rapidly reformat cognitive and metacognitive skills, upgrade intelligence and raise conscious experience into the higher energy levels. Hypnosis improves metacognition by reorganizing the survival-emotional-reward centers, smoothing the non-verbal pathways for effortless self-regulation. We concluded that the clinical hypnosis guarantees peak performance, innovation, success, and happiness in all areas of life. It can also play a significant role in education as a tool for dealing with the well-established learned weaknesses, for mental/emotional training and brain rewiring, facilitating learning, unlearning and relearning. Virtual reality hypnosis is a top promising technology assisting metacognitive training.
\end{abstract}

Keywords-clinical hypnosis, metacognition, intelligence, consciousness, subconsciousness training, unlearning, relearning, self-sabotage, brain rewiring, high performance, imagery, attention, inner vision, effortless self-regulation

\section{Introduction}

Clinical hypnosis enjoyed a period of tremendous growth in the $20^{\text {th }}$ century when became a valuable psychotherapeutic/psychoanalytic tool for behaviour modification [1]. However, the scientific history of hypnosis had started in $19^{\text {th }}$ century when Franz Anton Mesmer - based on the magnetism theory- practiced hypnosis-like techniques. Thereafter, many researchers (i.e. Di Faria, James Braid, Charcot, Pierre Janet, Freud) 
contributed to the development of hypnosis introducing new theories (i.e. theories about suggestion, dissociation, unconscious, placebo effect) [2]. Nowadays, respectful scientists (i.e Spiegel and many others) make experiments to uncover the brain areas and mechanisms associated with hypnosis [1]. Clinical hypnosis is already established in various clinical applications, especially pain management, obesity, smoking cessation, gastrointestinal disorders, asthma, diabetes, hypertension, immunological problems, dermatological diseases [3].

However, the origin of hypnosis can be dated back to ancient philosophies and medicines when healing was passing through self-knowledge, the road of liberation from all attachments keeping us away from enlightenment. For three millennia, Egyptian and Greek people -among them Parmenides and the father of modern medicine, Hippocrates- applied the first form of clinical hypnosis known as É $\gamma \kappa o i ́ \mu \eta \sigma \iota \varsigma$ (incubation, a trance-like sleep state) in the temples of Imhotep in Egypt and Asclepius in Greece. Similarly, Shamans, the first physician-healers investigated diseases and their treatment with a holistic approach according to which body, mind and environment build a dynamic interrelationship. Easter philosophies, traditional Chinese and Ayurveda medicine moved in the same direction [4]. Novel approaches in clinical hypnosis insist on non-dualist perspectives invoking chaotic complex systems theory and quantum mechanics [5].

The endeavor to define hypnosis from different theoretical perspectives has given rise to controversy. According to revised definition, hypnosis is a "state of consciousness involving focused attention and reduced peripheral awareness characterized by an enhanced capacity for response to suggestion" [6]. Hypnosis induces profound alterations in subjective experience following just a few words of suggestion. Individuals can quickly manifest atypical conscious experiences as well as override deeply entrenched processes [7]. Ericson et al. [8] argued that during hypnosis subjects are more receptive to lift the restrictions of their usual conscious sets and belief systems by experiencing new patterns of associations and modes of mental functioning.

According to Hartman et al. [9] hypnosis gives a "voice" to our unconscious mind to inform us about the disease that affects our bodies and minds. How we live, what we think and how we feel depends on our own individual "programming" that has been set from the moment of our conception and consists of our limitations as well as our immerse capabilities. However, the unconscious mind is still underestimated and viewed by many scientists as the shadow of a "real" conscious mind while extreme focus is given only on intentional, controllable, and accessible to awareness processes [10]. Norman [11] outlines that metacognition which represents the conscious mind is driven mostly by non-conscious factors which may make metacognition unhelpful. According to Bargh et al. [10] adults judgments and social behaviour are reinforced by automatic responses shaped during childhood, when imitative tendencies substituted the cognitive control structures. He also emphasizes that the future research should focus on how unconscious variables influence over consciousness and higher mental abilities.

In our latest studies, Drigas et al. proposed a new model of metacognition [12-13], which stands on 8 pillars of metacognition, 8 layers of consciousness and 8 intelligences. It is a multi-layered architecture defined by hierarchy and inspired by the 
Knowledge-Intelligence-Consciousness pyramid [14]. An important part of this metacognitive model was to describe the ways people develop their metacognition with a special focus on the factors that either facilitate or slow down metacognitive evolution and consciousness expansion Surprisingly, we realized that the majority of the factors that influence superior metacognitive abilities concern non-conscious operations. Doing the relevant research, we concluded that it is necessary to further explore the relationship between non-conscious processes and their impact on metacognition, intelligence, and consciousness [12-13]. And the best way was through hypnosis and especially clinical hypnosis, where an experienced and specialized professional give patients self-directed therapeutic suggestions [6].

The aim of the current study is to investigate the impact of clinical hypnosis on the three-fold "Metacognition-Consciousness-Intelligence". To achieve that purpose, we will structure our review on the 8 fundamental constituents of metacognition [12-13]. Furthermore, we will examine the role of virtual reality hypnosis in service of the 8 pillars model of metacognition.

\section{Clinical hypnosis in the light of the "8 pillars model of metacognition"}

\subsection{The role of clinical hypnosis in metacognitive knowledge}

The first pillar provides a greater understanding of how hypnosis affects the way the human brain works, learns, and grows its own capabilities. Clinical hypnosis can evoke profound changes in a series of cognitive and metacognitive mechanisms both during and after hypnosis. Hypnosis research has also shed light on cognitive phenomena that might otherwise go unnoticed $[12,15]$.

Attention. Virta et al. [16] examined the impact of hypnotic suggestions on attention processes. Participants were administered the neuropsychological task "Continuous Performance Test" to measure sustained and selective attention. The findings showed that hypnotic suggestions had an important impact on reaction times implying the improvement of attention.

Memory. Lindel $\varnothing v$ et al. [17], using a randomized controlled trial found that hypnotic suggestions can actively restore working memory performance in patients with acquired brain injury. Kihlstrom's et al. [15] pointed out that hypnosis can dissociate different forms of memory such as those of episodic and semantic memory allowing them to operate independently and accordingly with the therapeutic purposes. In addition, it facilitates memory accessibility and recall.

Perception. Hypnosis can modulate perceptual field in favour of tasks simplification, causing someone to miss existing visual stimuli or to infuse sensory input with nonexistent information [18]. It also improves sensory acuity especially in vision and audition [15,19]. A total of 87 studies consisting of 3.632 participants showed that hypnosis can modulate perception of pain reducing intensity while increasing tolerance [20]. 
Mental Imagery. Liggett et al. [21] investigated whether hypnosis improves mental imagery. Fourteen athletes were asked to imagine four situations in and out of hypnosis. Afterwards, participants reported their subjective impression of vividness on four dimensions - visual, auditory, kinaesthetic, and affective. The participants reported that the imagery after hypnosis was more intense and more effective for each dimension.

Language. Hypnotic suggestions improve reading speed and efficacy, reading and listening comprehension while they reduce time in verbal learning [22]. According to Cetin et al., hypnosis boosts learning and retrieval of recently learned second language vocabulary [23].

Problem solving. Hypnosis has been found to play a significant role in problem solving skills. Research in management training showed that it can serve as a useful tool for tapping and developing creative and innovative problem-solving skills. Hypnosis, also, has a significant impact on intuition an important factor in complex problem-solving [15, 24].

Decision making. Hypnosis allows individuals to make faster and more valuable decisions especially in situations of elevated impulsive behavior, desire, and emotional arousal. Indeed, fMRI data show that decisions after hypnosis activate the prefrontal areas responsible for valuable decisions [25].

Executive functions. Hypnosis enhances executive functions such as those of inhibition, emotional control and mental flexibility [26-28]. Hypnotic suggestions engage individuals in new and adaptive patterns of thinking, feeling and behaving. Participants adopt positive coping skills and cultivate resilience in the face of stressors [19].

Learning/Unlearning/Relearning. Nemeth et al., found that hypnosis can boost procedural learning allowing the individual to perform sequences of actions in an automated manner (i.e. language learning, handling musical instruments and computer devices). According to Nemeth et al. [29] hypnosis disconnects the brain areas responsible for conscious attentional control and activates those neural pathways that function effortlessly and automatically. Marinella et al. [30] found evidence that hypnosis can influence visual-spatial memory learning and has the capacity to induce neural plasticity. Schechtman et al. [31] found that in a state of sleep that resembles with hypnosis people under suggestion could prevent consolidation of memories learned during waking state.

Hormones \& neurotransmitters. Clinical hypnosis engages neurochemicals that support fundamental cognitive and metacognitive processes. According to Acunzo et al., [32] responsiveness to hypnotic suggestions involves dopamine, glutamate, gamma-aminobutyric acid, oxytocin and serotonin. These hormones play a major role in attention, memory, motivation and reward, motor control and other executive functions. In addition, they play a major role in synaptic plasticity.

Brain Oscillations. Hypnosis is closely linked to brain oscillations which play an important role in cognition. According to Jensen's et al. [33], there is evidence that some hypnotic responses are closely linked to power in the theta band and changes in gamma activity. These oscillations engage hippocampus, amygdala, basal ganglia, and neocortex playing a key role in processes such as those of attention, memory 
recording and retrieval, and may reflect new learning accompanied with reorganized neural pathways.

Neuroplasticity. Hypnosis is also associated with neuroplasticity and neurogenesis phenomena. Jiang et al. [28] used functional magnetic resonance imaging to examine brain activity and functional connectivity under hypnosis. During hypnosis, it was observed that prefrontal increased connectivity with insula and at the same time decreased connectivity with executive control network and default mode network. These changes in neural activity revealed the power of hypnosis to make changes in brain plasticity and connectivity. Horton et al. [34] found that highly hypnotizable individuals who were successfully exposed to hypnotic analgesia training had at least $30 \%$ larger rostrum, the area in corpus callosum which connects cerebral hemispheres each other along with different prefrontal areas. It is for that reason, it supports attentional processing, inhibition, cognitive flexibility, and various higher mental abilities.

\subsection{The role of clinical hypnosis in metacognitive awareness}

The second pillar of metacognition seeks the ways individuals acquire knowledge about themselves, awareness of their self-limitations and personal strengths. The ways individuals learn to apply the acquired knowledge considering all the possible variables of their situation, overcoming black-white dichotomy, and "seeing" beyond the visible spectrum [12-13].

As we mentioned, actions and conscious decisions are being undermined by forces that are possibly out of one's conscious awareness. Negative self-evaluations, dysfunctional cognitive patterns, previous knowledge and past experiences, unrealistic expectations, distorted beliefs, can be activated automatically slowing down metacognitive abilities such as those of monitoring, regulation, and adaptation [13].

Anxious people, for instance, tend to overfocus on metacognitive experiences disregarding present circumstances, overuse metacognitive strategies constantly monitoring for errors and threats, insist on unrealistically high expectations undermining motivations, self-evaluations, and new experiences [11].

Clinical hypnosis examines clinical signs attributable to certain health problem as the 'shell' that covers up the root causes of alleged clinical pathology and helps patients to do so. Woodard [35] utilized perceptually oriented hypnosis to alter the distorted perceptions of an eleven-year-old girl who wrongly believed that she had bipolar disorder. Hypnosis revealed that behind irritability, emotional suffering, mood swings and aggressive behaviour smouldered the constant fear of coping with change, the learned helplessness, anger, and trauma. The therapist used hypnosis successfully to restore trust, the antidote to fear, to reorganize self, to expand the patient's perception and self-awareness. After hypnosis the patient developed all those characteristics that permitted her to enhance her potential and expand her perceptual universe.

Poon [36] used hypnosis in helping an adult woman survivor of childhood sexual abuse. The woman struggled with trauma related symptoms including poor affect regulation, hyperarousal, intrusive thoughts stuck in the mind, self-destructive behaviour, disturbances of self-schema, shame, isolation, avoidance, lack of motivation. As she mentioned, she found herself unprotected, damaged, and unloved because of 
abuse and her mother's rejection. After hypnosis, the patient began to be aware of the feelings related to abuse, she understood that that there was a wounded child inside her with plenty positive characteristics such as self-appreciation, resilience, courage, sacrifice. She restructured the meaning of trauma, letting go of the past, accepting the conflicting feelings. Finally, she learned to recognize, communicate, and adapt emotional experiences to return to a comfortable state of arousal.

De Vos [37] investigated whether hypnosis induced mental training programmes could alter self-concept and lead to overall academic performance. 120 undergraduate psychology students were divided into experimental and control groups. One of the experimental groups was exposed to active alert hypnosis and the other to relaxation hypnosis in which a variety of hypnotic skills were instructed. The results showed that hypnosis groups strengthened self-concept, a fundamental facilitator of selfawareness.

Vasel et al. [38] aimed at ego-strengthening and decreasing self-talk through hypnosis in 30 female heads of households. This group is very vulnerable to face stigma, insecurity and psychological problems. The results showed that there was a significant difference between experimental and control group. The authors concluded that hypnosis helped participants to build self-confidence and consequently to remove from negative to more positive and rational self-talk. Inner speech/dialogue reflects the individual's belief system and thus can play a significant role -either as facilitator or inhibitor- in self-regulation processes.

\subsection{The role of clinical hypnosis in self-observation}

Self-observation refers to the inner vision that enlightens the sources of behaviors [12].

Although many people with unhealthy or self-destructive behaviors may be aware of their automatic behaviors, they find it impossible to realize what they are really doing. Lifshitz et al. [7] proposed that hypnosis helps subjects to suspend narrative judgments, loosen deep-seated patterns of conceptual elaboration and make a profound shift in common modes of attention holding attention clear and open to the ongoing process of experience, supporting non-judgmental meta-awareness of the present moment. Hypnotic suggestions work below conscious level and impel subjects to improve phenomenological awareness by noticing their experience without interference from the willful act of observation and verbal overshadowing processes.

Dillengurger et al. [39] used hypnosis to facilitate self-monitoring in a typically developing teenager with multiple tics. Under hypnosis, the patient was instructed to raise her index finger each time she identified tic behaviors. For instance, whenever the patient was engaged in eye-rolling, the therapist said, "you are eye-rolling" and then she had to raise the index finger. Afterwards, she was instructed to engage in similar competing responses when she was engaged in tics. For instance, when she jerked her foot, she was instructed to pull her toes up. In the third stage, the hypnotherapist asked her to imagine and observe that muscles are gradually being relaxed. Finally, she was instructed to apply self-monitoring during self-induced relaxation training. The frequency of tics was reduced. After 10 weeks, tics started to cease 
completely. Eighteen months after treatment completion, tics had not recurred, the patient was doing well at school and appeared more confident. Thus, this study showed that hypnosis can cultivate self-observation skills with a long-term impact.

According to McNeal's et al. review [40] ego-strengthening hypnosis increases the effectiveness of ego functions, the part of the mind responsible for agency, action, and executive control. In conscious states, the ego observes, perceives, acts, and organizes experience. It is the sense of "I". When ego-strengthening has occurred, the self, the sense of "Me" is experienced as stronger, more adequate, and more effective in dealing with both the internal and external world.

Witz et al. [41] used various hypnotic interventions to treat two patients with Huntington's disease, a disorder of the central nervous system. It was found that hypnosis enhanced self-monitoring skills which were lost. Gradually, they begun to uncover and work through repressed conflicts and develop the inner nurturant therapist. Patients were able to monitor and control movement, so the number of falls decreased.

\subsection{The role of clinical hypnosis in self-regulation}

Self-regulation seeks to resolve the conflicts that disrupt the upgrowth road towards self-development [12-13].

Zahedi et al. [27] investigated the effectiveness of post-hypnotic suggestions in inhibiting the desire for unhealthy food choices. The suggestions aimed at impelling participants to associate a sound with a feeling of lightness accompanied with a voracious desire for healthy food. The results showed that post-hypnotic suggestions enhanced suppression of prepotent but inappropriate responses. In addition, the participants improved proactive control to inhibit food-related emotions. Interestingly, the researchers observed that participants quickened the rejection of unhealthy items implying improved monitoring and processing abilities. The suggestions appeared to neutralize the initial positive perceptual bias towards unhealthy food implicitly cultivating new positive beliefs and reward associations for healthy food. This study reveals the power of hypnosis on regulating cognitive and affective processes incited by reward system.

People with low levels of self-control and high levels of impulsivity (i.e gambling disorders, ADHD) have difficulty in waiting for delayed rewards resulting in inability to reach long-term goals. Schmidt et al. [42] hypnotized 24 participants and gave them a suggestion to feel safe, because the feeling of security may reduce the need for immediate reward. Then, they recorded the electroencephalogram to measure participants' brain responses to immediate and delayed rewards while they played a delayed gratification game. The results showed that hypnotic suggestions modified the way that participants evaluated rewards reducing their physical tendency to devalue future or lower rewards. In the hypnosis condition, it was also observed that participants rated all rewards as less arousing compared to the control condition. These results mean improvement in self-control processes.

Hypnosis could be an effective self-regulation strategy for weakening addicted behaviours as well as enhancing behavioural modification. Hasan et al. [43] conducted a single center randomized study to examine the efficacy of hypnosis alone as well as 
hypnosis with nicotine replacement therapy (NRT) in comparison with conventional NRT for smoking cessation. During trance state, the hypnosis group was suggested to visualize good health and healing, dissociate pleasant experience from smoking, create negative affectivity towards nicotine and cultivate self-worth. The sessions were also individualized according to each patients' reasons and triggers to enhance willingness to stop smoking. It was found that hypnosis alone was more effective in abstaining from smoking (three times more likely compared with NRT group).

Clinical hypnosis seems to play a significant role in emotional regulation. Iglesias et al. [44] examined the effectiveness of hypnosis in a case of preschool age child with oppositional defiant disorder concomitant emotional dysregulation and secondary behavioral disruptiveness. The results showed a significant reduction of the outof-control episodes. The child gained the ability to monitor, control and change emotional reactions.

\subsection{The role of clinical hypnosis in adaptability}

Adaptation allows individuals to finetune their internal and external perceptions with their actions [12-13].

Faerman et al. [26] provided evidence that the tendency to respond to hypnosis is linked to cognitive flexibility. The researchers selected 72 participants who firstly completed the Harvard Group Scale of Hypnotic Susceptibility and afterwards two neuropsychological tests that assess the cognitive phenomenon known as perseveration. Perseveration happens when one applies previously learned -but incorrect- rules instead of newly learned rules. The researchers found that the ability to respond to hypnosis is associated with lower preservation, in other words with improved cognitive flexibility. This ability to adapt to new information despite the physical tendency to automatically apply previous experiences implies that hypnosis may have a simultaneous impact on other executive control functions such as inhibition.

Roslim et al. [45] reviewed the contemporary scientific research on the effectiveness of hypnotherapy for obesity and overweight problems. A total of 7 studies and 539 participants was included. The results suggested that hypnosis helps most patients to be more adaptable. Specifically, most participants changed lifestyle, dietary habits and eating behaviours increasing, for instance, physical activity and at the same time reducing dietary intake. In addition, they were more motivated to change and achieve personal satisfaction. Their attitude was more positive accompanied with a sense of self-acceptance about their body appearance. Their ability to be more flexible was enhanced because of hypnosis positive impact on self-awareness as well as selfregulation skills.

Implicit attitudes about individuals and situations are considered as an important inhibitor in metacognitive development in terms of adaptation since they seem to be out of conscious control and thus resistant to change. Van Dessel et al. [46] examined whether hypnosis could change those automatic behaviours. Participants read positive or negative information about two fictional social groups or learned to associate one person with positive words and pictures and another person with negative words and pictures. Then, half participants were hypnotized, whereas the rest went through a 
relaxation phase. Later, all participants were given information that contradicted the information they had received earlier. The results (measured by the Implicit Association Test and an affect-misattribution test) showed that only hypnotized participants could change their implicit attitudes. The authors concluded that hypnosis facilitates rapid change of implicit and automatic behaviours boosting self-regulation and thus making people more adaptive.

\subsection{The role of clinical hypnosis in recognition}

Recognition permits people to recognize what the self-imposed limitations does not allow them to recognize, to "see" the reasons of the behaviors [12-13].

Hypnosis may help individuals to recognize abilities which were possibly already existent but unacknowledged. Mazini et al. [47] investigated the effects of hypnotic induction on muscular strength in twelve men with experience in resistance training. Researchers used the one-repetition maximum (1RM) test which practically measures the maximal weight an individual can lift. Participants were tested in conditions with hypnosis and without hypnosis. The main goal of hypnosis intervention was to bring participants in an empty-minded state and order them to increase strength. The results showed that strength performance was significantly better after hypnotic induction. This study gives evidence that with the power of mind people can experience abilities such as strength far above than those usually achieved.

After hypnosis, people develop the metacognitive ability to recognize not only the causes of an inappropriate behavior but also those personal and positive characteristics as well as motives that counterbalance the negative ones. Hill et al. [48] used hypnosis to help a woman with avoidance behavior and driving phobia who was engaged in a number of accidents. After four sessions with hypnosis, she achieved her goal of making a long-distance trip by car. Hypnosis helped her to recognize that there was no real risk of accident. She also realized that her avoidance behaviour was due to fear, lack of confidence, and constant negative judgements. After hypnosis, she stated that she was aware of her real strengths which enabled her to focus on personal and professional goals rather than on hypothetical risks.

\subsection{The role of clinical hypnosis in discrimination}

Discrimination concerns the metacognitive ability to discern between good and bad ways of living and willfully choose the desire for Good [12-13].

Kaiser [49] examined the role of hypnosis in enhancing discrimination skills to children with anxiety and psychological reactivity. According to this study, hypnosis is an ideal strategy that interrupts with unproductive patterns of thought and fosters new patterns of more realistic and accurate discrimination capacities and sturdier psychophysiological self-regulation skills. After hypnosis, children gradually tend to reduce bias, overestimations as well as over-interpretations about threats while they expand their ability to discern thoughts from emotions, stories from facts, lies from the truth. 
Iglesias et al. [50] describes three pediatric cases of trichotillomania treated with hypnosis. It is noteworthy that the children had presented total lack of awareness of their scalp hair pulling behaviors, until they had pulled off clumps of hair. The therapists recognized that behind all patients' behaviors was hidden the repressed anger due to their authoritarian home. Thus, the therapist decided to use direct hypnotic suggestions as an exercise of becoming free to choose between the impulsive behavior and regulated behavior. During hypnosis they instructed participants to be alert, observe, be intensely aware whenever the impulse comes out and decide if they want to execute the action. After only five visits the bad behavior stopped. The intervention was effective for various reasons. This technique was designed to resolve the underlying dynamics of the behavior in question. In terms of metacognition, hypnotic suggestions indirectly pointed out those processes that are necessary for developing discrimination skills such as observation, awareness, regulation. Thus, this study showed that hypnosis can cultivate discrimination skills needed for making useful decision, to set limits facilitating the normal development and autonomy.

\subsection{The role of clinical hypnosis in Mnemosyne}

Mnemosyne represents the internalized knowledge that purifies, awakens, and drives human towards the road of Anelixis (upgrowth) [12-13].

Fromm et al. [51] examined the case of a 26-year-old Japanese-American who thought he knew no Japanese. When hypnotically age regressed to levels below the age of four, he spontaneously and unexpectedly spoke Japanese for about 20 minutes. When the therapist progressed him to the age of 7, he spontaneously reverted to English. The therapist used various methods to confirm her hypothesis. For instance, when she used an English word which sounds nearly the same with a Japanese and belongs to a 3-year-old child vocabulary, the patient started speaking Japanese. Afterwards, the therapist asked the patient to remember his feelings during trance state. According to the patient report, he felt like his lips suddenly moved without being aware of the word's meanings. Then, he revealed that he was only a baby when he learned to speak mostly Japanese. Later his parents stopped talking Japanese to him and English became the only language he spoke. He also admitted that he had a strong desire to be considered a full American in fear of being characterized as a secondclass citizen. Later, in waking state, when he listened to the Japanese part of his tape, he claimed that he could recognize his Japanese as 'real'. After recalling this knowledge, he felt liberated from conflicts about his real identity. The author concluded that through hypnosis, the patient made a dynamic return to the knowledge, which was repressed, forgotten -but not lost- by defensive mechanisms. After lifting the repression barrier, the dormant memory traces 'awoke' making this knowledge available and more productive in the waking state.

Hypnosis can lead individuals in a state of awareness capable of unblocking memories or recalling details relating to past experiences with extreme accuracy. Wester et al. [52] described ten forensic hypnosis cases including murders, kidnapping, bank robberies and bombing. In all cases, witnesses had a difficulty in recalling faces, events, and important details possibly because they were exposed to intensely emo- 
tional situations. The hypnotherapists used various and well-deigned methods to help memory recalling. After hypnosis, witnesses could describe faces and events in absolute detail, even recall license plate numbers. A witness who could not recall during hypnosis, was given post-hypnotic suggestion to continue to search during waking state. Indeed, a few days later, she remembered the missing information. This study also reveals that people record and store much more information than they are aware. Although it seems that this knowledge is inaccessible, it can be excavated and applied in waking state.

Mnemosyne is all about being fully present. According to Ruysschaert et al. [53] hypnosis aims at planting the seeds of happiness in terms of a pleasant, good, meaningful, and full life. During hypnosis the participants are invited to develop full awareness, be connected to what they are doing here and now, to a state where doing and being melt together. In addition, hypnosis brings a positive emotional state which matches with the establishment of positive mental health, suggesting patients to go to a nice, safe, pleasant experience, smile at their problems and feel gratitude. After a few sessions, patients claim that they develop the tendency to remember the little things they enjoyed. From there, spontaneously other positive memories come up as a chain of fulfilment and joy. In Ego-strengthening hypnosis, participants cultivate inner strength reliving an experience with acceptance, remembering how they dealt with obstacles, how they found courage to continue efforts in favour of a greater-good goal. For people who decide via hypnotic suggestions to be happier and orient themselves to positive future where all talents and skills are mobilized, there is clear likelihood to make behavioural changes in waking state to facilitate greater well-being. Suggestions are given to store the feelings, internalize them, and see these as a special gift they take with them on their way back into the present. Finally, in some cases, hypnosis awakens participants' spiritual awareness bringing them closer to the big life questions.

\section{Virtual reality hypnosis in service of the 8 pillars model of metacognition}

Virtual reality hypnosis (VRH) is considered a promising technology which has the potential to contribute to the widespread use of hypnosis in non-clinical settings. VRH applies three-dimensional, immersive technology to guide the patient, following the same steps used when hypnosis is induced through an interpersonal process. It also facilitates receptivity replacing many of the stimuli that the patients struggle to imagine via verbal cueing from the therapist [54]. A considerable amount of literature gives evidence that VRH is aligned with the purposes of the 8 Pillars Models of Metacognition:

- Metacognitive knowledge: Improves cognitive and metacognitive abilities such as attention, memory, concentration, perception, mental imagery and problem solving [54-56] 
- Metacognitive awareness: VRH helps participants to apply hypnosis strategies in real situations to cope with stressful situations to alter misconceptions about possible dangers [57].

- Self-observation: VRH facilitates participants -especially those in difficulty- to focus, visualize and observe themselves in various situations according to the therapeutic purposes [58]

- Self-Regulation: Thompson et al. [55] concluded that VRH surpasses traditional methods of hypnosis since it improves participants' engagement promising better ability to regulate distraction, tiredness, and mood. Teeley et al. [59] found that virtual reality hypnosis helped patients to regulate the subjective feeling of pain. The virtual environment helped patients to orient their attention away from the painful stimuli. In addition, patients reduced the time spent in thinking of pain and unpleasantness background of pain.

- Adaptation: Virtual reality gradually exposes patients in fearful situations as a method of de-sensitization. Hirsch [60] helped a treatment-resistant patient with aviophobia. The patients became habituated to the flight applying new adaptive strategies during flying. For instance, he was reframing actual situations as being simulation of the virtual reality exposure.

- Recognition: VRH helps patients to forget painful experiences making it easier to recognize the importance of being emotionally calm, looking for positive experiences [61]

- Discrimination: Virtual reality exposure in target situations combined with hypnotic techniques made a patient with phobia to discern real from hypothetical threats, negative thoughts from positive outcomes in personal and professional level [Hirch]

- Mnemosyne: According to Opris et al. [62] hypnotic suggestions immerse participants in the virtual world deepening the sense of presence. The sense of presence awakens individuals facilitating reality judgements, emotional involvement, and feelings of satisfaction. Being present is the key to overcome symptoms of anxiety and depression [56, 62].

\section{Discussion and conclusions}

In this review study we summarized a series of research and case studies in view of the 8 pillars model of metacognition with the aim to answer the question: Is clinical hypnosis effective in helping people improve their metacognitive abilities? What is the impact on Intelligence? Can hypnosis make people more conscious? According to the findings of this review there is evidence that clinical hypnosis effectively and rapidly:

- Improves cognitive and metacognitive abilities and especially the higher mental abilities.

- Boosts learning, unlearning and relearning.

- Readjusts homeostasis, promotes neurogenesis, neuroplasticity and reorganization of neural connectivity. 
- Reorganizes self, expands perception, and ensures better self-awareness about the strengths that are overshadowed by self-imposed limitations.

- Facilitates inner vision.

- Supports non-judgmental meta-awareness of the present moment without interference from wilful act of observation and verbal overshadowing processes.

- Enhances executive functions (monitoring, faster inhibition, cognitive flexibility) and regulates cognitive and affective processes incited by reward system.

- Motivates change (in habits, beliefs, lifestyle, implicit evaluations), adaptation and self-acceptance.

- Neutralizes perceptual bias and implicitly cultivates new positive beliefs and reward associations

- Helps people to recognize -in an empty minded state- the reasons of the behaviours, the hidden powers of the mind experiencing abilities far above those usually achieved

- Reduces bias, overestimations and over-interpretations about threats while expanding the ability to discern productive from self-destructive beliefs.

- Liberates from conflicts about the real self-identity, lifts the repression barriers, awakes the dormant or blocked memory traces making the internalized knowledge available and more productive in the waking state.

- Plants the seeds of happiness: Hypnosis helps individuals to store the suggested positive feelings, internalize them, and see these as a gift on the way back into the present.

The above benefits of hypnosis are just a few given the wide range of its applications. In any case, this research has shown that clinical hypnosis can effectively and rapidly improve cognitive and metacognitive abilities, intelligence and conscious experience and lead people in making profound and positive changes in every strata of life. Clinical hypnosis gives direct access and processability to the well-established learned weaknesses powered by the survival, reward and emotional centres which operate in the lower levels of the consciousness spectrum and conserves the inner resources needed to make a leap quicker than deterioration and proceed to the higher energy levels of consciousness and human existence (Figure1) [12-14,63]. Clinical hypnosis has the potential to resolve conflicts and prevent self-sabotage through subconscious reformatting. It could also play a significant role in the future education facilitating unlearning and relearning though the activation of the non-verbal pathways of effortless self-regulation [64]. Virtual reality hypnosis is a promising technology and could play a significant role in future metacognitive training. 


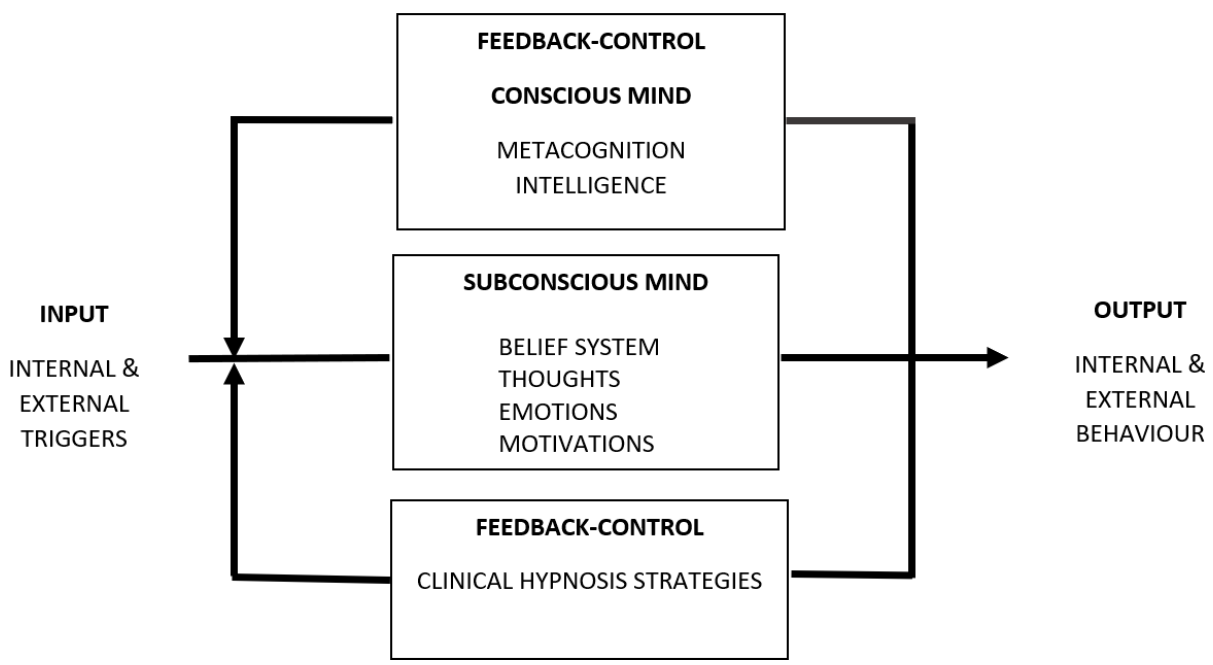

Fig. 1. The two major control-regulation systems represented via system's control theorymodelling

\section{$5 \quad$ References}

[1] Green, J. P., Laurence, J. R., \& Lynn, S. J. (2014). Hypnosis and psychotherapy: From Mesmer to mindfulness. Psychology of Consciousness: Theory, Research, and Practice, 1(2), 199. https://doi.org/10.1037/cns0000015

[2] Hammond, D. C. (2013). A review of the history of hypnosis through the late 19th century. American Journal of Clinical Hypnosis, 56(2), 174-191. https://doi.org/10.1080/00029157 .2013 .826172

[3] Mendoza, M. E., \& Capafons, A. (2009). Efficacy of clinical hypnosis: A summary of its empirical evidence. Papeles del Psicólogo.

[4] Facco, E., \& Tagliagambe, S. (2021). Learning From the Past: From Incubation in Ancient Egypt and Greece to Modern Hypnosis. Advances in Social Sciences Research Journal, 8(7), 268-285. https://doi.org/10.14738/assri.87.10541

[5] De Benedittis, G. (2020). From quantum physics to quantum hypnosis: A quantum mind perspective. International Journal of Clinical and Experimental Hypnosis, 68(4), 433-450. https://doi.org/10.1080/00207144.2020.1799380

[6] Elkins, G. R., Barabasz, A. F., Council, J. R., \& Spiegel, D. (2015). Advancing research and practice: The revised APA Division 30 definition of hypnosis. American Journal of Clinical Hypnosis, 57(4), 378-385. https://doi.org/10.1080/00029157.2015.1011465

[7] Lifshitz, M., Cusumano, E. P., \& Raz, A. (2013). Hypnosis as neurophenomenology. Frontiers in human neuroscience, 7, 469. https://doi.org/10.3389/fnhum.2013.00469

[8] Erickson, M. H., Rossi, E. L., \& Rossi, S. I. (1976). Hypnotic realities: The induction of clinical hypnosis and forms of indirect suggestion. Oxford, UK: Irvington

[9] Hartman, D., \& Zimberoff, D. (2011). Hypnosis and hypnotherapy in the milieu of integrative medicine: Healing the mind/body/spirit. Journal of Heart-Centered Therapies, 14(1), 41.

[10] Bargh, J. A., \& Morsella, E. (2008). The unconscious mind. Perspectives on psychological science, 3(1), 73-79. https://doi.org/10.1111/j.1745-6916.2008.00064.X 
[11] Norman, E. (2020). Why metacognition Is not always helpful. Frontiers in psychology, 11, 1537.

[12] Drigas, A., \& Mitsea, E. (2020). The 8 pillars of Metacognition. International Journal of Emerging Technologies in Learning (iJET), 15(21), 162-178. http://dx.doi.org/10.3991/ ijet.v15i21.14907

[13] Drigas, A., \& Mitsea, E. (2021). 8 Pillars X 8 Layers Model of Metacognition: Educational Strategies, Exercises \&Trainings. International Journal of Online \& Biomedical Engineering, 17(8). https://doi.org/10.3991/ijoe.v17i08.23563

[14] Drigas, A. S., \& Pappas, M. A. (2017). The consciousness-intelligence-knowledge pyramid: an 8x8 layer model. International Journal of Recent Contributions from Engineering, Science \& IT (iJES), 5(3), 14-25. https://doi.org/10.3991/ijes.v5i3.7680

[15] Kihlstrom, J. F. (2014). Hypnosis and cognition. Psychology of Consciousness: Theory, Research, and Practice, 1(2), 139.

[16] Virta, M., Hiltunen, S., Mattsson, M., \& Kallio, S. (2015). The impact of hypnotic suggestions on reaction times in continuous performance test in adults with ADHD and healthy controls. Plos one, 10(5), e0126497. https://doi.org/10.1371/journal.pone.0126497

[17] Lindeløv, J. K., Overgaard, R., \& Overgaard, M. (2017).Improving working memory performance in brain-injured patients using hypnotic suggestion: a randomized controlled trial. https://doi.org/10.31234/osf.io/n9kbf

[18] Landry, M., Da Silva Castanheira, J., Sackur, J., \& Raz, A. (2021). Difficult turned easy: Suggestion renders a challenging visual task simple. Psychological science, 32(1), 39-49. http://dx.doi.org/10.1177/0956797620954856

[19] Terhune, D. B., Cleeremans, A., Raz, A., \& Lynn, S. J. (2017). Hypnosis and top-down regulation of consciousness. Neuroscience \& Biobehavioral Reviews, 81, 59-74. https://doi.org/10.1016/j.neubiorev.2017.02.002

[20] Thompson, T., Terhune, D. B., Oram, C., Sharangparni, J., Rouf, R., Solmi, M., \& Stubbs, B. (2019). The effectiveness of hypnosis for pain relief: A systematic review and metaanalysis of 85 controlled experimental trials. Neuroscience \& Biobehavioral Reviews, 99, 298-310. https://doi.org/10.1016/j.neubiorev.2019.02.013

[21] Liggett, D. R. (2000). Enhancing imagery through hypnosis: a performance aid for athletes. American Journal of clinical hypnosis, 43(2), 149-157. https://doi.org/10.1080/ 00029157.2000 .10404267

[22] Wark, D. M. (2011). Traditional and alert hypnosis for education: A literature review. American Journal of Clinical Hypnosis, 54(2), 96-106. https://doi.org/10.1080/ $\underline{00029157.2011 .605481}$

[23] Çetin, Y., Çimen, O. A., \& Yetkiner, Z. E. (2016). Using hypnosis to enhance learning second language vocabulary. American Journal of Clinical Hypnosis, 58(4), 399-410. https://doi.org/10.1080/00029157.2015.1121373

[24] Agor, W. H. (1997). The Use of Hypnosis to Induce Creative Problem Solving: Potential Applications in Public Sector Management Training. Review of Public Personnel Administration, 17(2), 73-79. https://doi.org/10.1177/0734371x9701700206

[25] Ludwig, V. U., Stelzel, C., Krutiak, H., Magrabi, A., Steimke, R., Paschke, L. M., ... \& Walter, H. (2014). The suggestible brain: posthypnotic effects on value-based decisionmaking. Social cognitive and affective neuroscience, 9(9), 1281-1288. https://doi.org/ $\underline{10.1093 / \mathrm{scan} / \mathrm{nst} 110}$

[26] Faerman, A., \& Spiegel, D. (2021). Shared cognitive mechanisms of hypnotizability with executive functioning and information salience. Scientific Reports, 11(1), 1-12. https://doi.org/10.1038/s41598-021-84954-8 
[27] Zahedi, A., Łuczak, A., \& Sommer, W. (2020). Modification of food preferences by posthypnotic suggestions: An event-related brain potential study. Appetite, 151, 104713. http://dx.doi.org/10.1016/j.appet.2020.104713

[28] Jiang, H., White, M. P., Greicius, M. D., Waelde, L. C., \& Spiegel, D. (2017). Brain activity and functional connectivity associated with hypnosis. Cerebral cortex, 27(8), 40834093. https://doi.org/10.1093/cercor/bhw220

[29] Nemeth, D., Janacsek, K., Polner, B., \& Kovacs, Z. A. (2013). Boosting human learning by hypnosis. Cerebral cortex, 23(4), 801-805. https://doi.org/10.1093/cercor/bhs068

[30] Marinella, C., Tiziana, R., Giuseppe, V., Antonino, G., Di Gregorio, G., \& Andrea, B. (2020). Hypnosis and learning: Pilot study on a group of students. Journal of Complementary and Integrative Medicine, 17(2). https://doi.org/10.1515/jcim-2017-0082

[31] Schechtman, E., Witkowski, S., Lampe, A., Wilson, B. J., \& Paller, K. A. (2020). Targeted memory reactivation during sleep boosts intentional forgetting of spatial locations. Scientific reports, 10(1), 1-9. https://doi.org/10.1038/s41598-020-61784-8

[32] Acunzo, D. J., Oakley, D. A., \& Terhune, D. B. (2021). The neurochemistry of hypnotic suggestion. American Journal of Clinical Hypnosis, 63(4), 355-371. https://doi.org/ $\underline{10.1080 / 00029157.2020 .1865869}$

[33] Jensen, M. P., Adachi, T., \& Hakimian, S. (2015). Brain oscillations, hypnosis, and hypnotizability. American Journal of Clinical Hypnosis, 57(3), 230-253. https://doi.org/ $\underline{10.1080 / 00029157.2014 .976786}$

[34] Horton, J. E., Crawford, H. J., Harrington, G., \& Downs III, J. H. (2004). Increased anterior corpus callosum size associated positively with hypnotizability and the ability to control pain. Brain, 127(8), 1741-1747. https://doi.org/10.1093/brain/awh196

[35] Woodard, F. J. (2014). Perceptually-Oriented Hypnosis: Removing a Socially Learned Pathology and Developing Adequacy: The Case of Invisible Girl. Psychological reports, 115(2), 545-564. https://doi.org/10.2466/02.pr0.115c24z9

[36] Poon, M. W. L. (2007). The value of using hypnosis in helping an adult survivor of childhood sexual abuse. Contemporary Hypnosis, 24(1), 30-37. https://doi.org/10.1002/ch.324

[37] De Vos, H. M., \& Louw, D. A. (2009). Hypnosis-induced mental training programmes as a strategy to improve the self-concept of students. Higher Education, 57(2), 141-154. https://doi.org/10.1007/s10734-008-9138-0

[38] Vasel, M. Y., Farhadi, M., Paidar, M. R. Z., \& Chegini, A. A. (2016). The efficacy of hypnotherapy for ego strengthening and negative self-talk in female heads of households. Sleep and Hypnosis, 18(4), 74-81. https://doi.org/10.5350/sleep.hypn.2016.18.0111

[39] Dillenburger, K., \& Keenan, M. (2003). Using hypnosis to facilitate direct observation of multiple tics and self-monitoring in a typically developing teenager. Behavior therapy, 34(1), 117-125. https://doi.org/10.1016/s0005-7894(03)80025-4

[40] McNeal, S. (2020). Hypnotic Ego-strengthening: Where We've Been and the Road Ahead. American Journal of Clinical Hypnosis, 62(4), 392-408. https://doi.org/10.1080/00029157. $\underline{2019.1709151}$

[41] Witz, M., \& Kahn, S. (1991). Hypnosis and the treatment of Huntington's disease. American Journal of Clinical Hypnosis, 34(2), 79-90. https://doi.org/10.1080/00029157. 1991.10402967

[42] Schmidt, B., \& Holroyd, C. B. (2021). Hypnotic suggestions of safety reduce neuronal signals of delay discounting. Scientific reports, 11(1), 1-11. https://doi.org/10.1038/ $\underline{\text { s41598-021-81572-2 }}$

[43] Hasan, F. M., Zagarins, S. E., Pischke, K. M., Saiyed, S., Bettencourt, A. M., Beal, L., ... $\&$ McCleary, N. (2014). Hypnotherapy is more effective than nicotine replacement therapy 
Paper-Clinical Hypnosis \& VR, Subconscious Restructuring-Brain Rewiring \& the Entanglement with...

for smoking cessation: results of a randomized controlled trial. Complementary therapies in medicine, 22(1), 1-8. https://doi.org/10.1016/j.ctim.2013.12.012

[44] Iglesias, A., \& Iglesias1, A. (2014). Pediatric Emotional Dysregulation and Behavioral Disruptiveness Treated With Hypnosis: A Time-Series Design. International Journal of Clinical and Experimental Hypnosis, 62(1), 70-83. https://doi.org/10.1080/00207144.2013. $\underline{841480}$

[45] Roslim, N. A., Ahmad, A., Mansor, M., Aung, M. M. T., Hamzah, F., Hassan, H., \& Lua, P. L. (2020). Hypnotherapy for overweight and obese patients: A narrative review. Journal of integrative medicine. https://doi.org/10.1016/j.joim.2020.10.006

[46] Van Dessel, P., \& De Houwer, J. (2019). Hypnotic suggestions can induce rapid change in implicit attitudes. Psychological science, 30(9), 1362-1370. https://doi.org/10.1177\% 2F0956797619865183

[47] Mazini Filho, M. L., Savoia, R. P., de Castro, J. B. P., Moreira, O. C., de Oliveira Venturini, G. R., Curty, V. M., ... \& Ferreira, C. (2018). Effects of Hypnotic Induction on Muscular Strength in Men with Experience in Resistance Training. Journal of Exercise Physiology Online, 21(1), 52-62.

[48] Hill, R., \& Bannon- Ryder, G. (2005). The use of hypnosis in the treatment of driving phobia. Contemporary Hypnosis, 22(2), 99-103. https://doi.org/10.1002/ch.29

[49] Kaiser, P. (2014). Childhood anxiety and psychophysiological reactivity: Hypnosis to build discrimination and self-regulation skills. American Journal of Clinical Hypnosis, 56(4), 343-367. https://doi.org/10.1080/00029157.2014.884487

[50] Iglesias, A. (2003). Hypnosis as a vehicle for choice and self-agency in the treatment of children with trichotillomania. American Journal of Clinical Hypnosis, 46(2), 129-137. https://doi.org/10.1080/00029157.2003.10403583

[51] Fromm, E. (1970). Age regression with unexpected reappearance of a repressed c3ildhood language. International Journal of Clinical and Experimental Hypnosis, 18(2), 79-88. https://doi.org/10.1080/00207147008415906

[52] Wester, W. C., \& Hammond, D. C. (2011). Solving crimes with hypnosis. American journal of clinical hypnosis, 53(4), 249-263. https://doi.org/10.1080/00029157.2011.10404355

[53] Ruysschaert, N. (2009). (Self) hypnosis in the prevention of burnout and compassion fatigue for caregivers: theory and induction. Contemporary Hypnosis, 26(3), 159-172. https://doi.org/10.1002/ch.382

[54] Askay, S. W., Patterson, D. R., \& Sharar, S. R. (2009). Virtual reality hypnosis. Contemporary Hypnosis, 26(1), 40-47. https://doi.org/10.1002/ch.371

[55] Thompson, T., Steffert, T., Steed, A., \& Gruzelier, J. (2010). A randomized controlled trial of the effects of hypnosis with 3-D virtual reality animation on tiredness, mood, and salivary cortisol. International Journal of Clinical and Experimental Hypnosis, 59(1), 122-142. https://doi.org/10.1080/00207144.2011.522917

[56] Zhao, X., You, X., Shi, C., \& Gan, S. (2015). Hypnosis therapy using augmented reality technology: treatment for psychological stress and anxiety. Behaviour \& Information Technology, 34(6), 646-653. https://doi.org/10.1080/0144929X.2015.1022223

[57] Lupu, V., Matu, S., \& Lupu, I. R. (2019). Cognitive-behavioral hypnotherapy augmented with virtual reality exposure in flight phobia: a case study. Journal of Evidence-Based Psychotherapies, 19(1). https://doi.org/10.24193/jebp.2019.1.3

[58] Patterson, D. R., Tininenko, J. R., Schmidt, A. E., \& Sharar, S. R. (2004). Virtual reality hypnosis: a case report. International Journal of Clinical and Experimental Hypnosis, 52(1), 27-38. https://doi.org/10.1076/iceh.52.1.27.23925

[59] Teeley, A. M., Soltani, M., Wiechman, S. A., Jensen, M. P., Sharar, S. R., \& Patterson, D. R. (2012). Virtual reality hypnosis pain control in the treatment of multiple fractures: a 
Paper-Clinical Hypnosis \& VR, Subconscious Restructuring-Brain Rewiring \& the Entanglement with...

case series. American journal of clinical hypnosis, 54(3), 184-194. https://doi.org/ $\underline{10.1080 / 00029157.2011 .619593}$

[60] Hirsch, J. A. (2012). Virtual reality exposure therapy and hypnosis for flying phobia in a treatment-resistant patient: a case report. American Journal of Clinical Hypnosis, 55(2), 168-173. https://doi.org/10.1080/00029157.2011.639587

[61] Patterson, D. R., Jensen, M. P., Wiechman, S. A., \& Sharar, S. R. (2010). Virtual reality hypnosis for pain associated with recovery from physical trauma. Intl. Journal of Clinical and Experimental Hypnosis, 58(3), 288-300. https://doi.org/10.1080/00207141003760595

[62] Opris, D., Enea, V., Pop, A., \& Dafinoiu, I. (2011). Hypnotic suggestions effect on sense of presence in virtual reality. A brief report”. Erdélyi Pszichológiai Szemle, 12(1), 13-22.

[63] Drigas, A., \& Mitsea, E. (2021). Metacognition, Stress-Relaxation Balance \& Related Hormones. Int. J. Recent Contributions Eng. Sci. IT, 9(1), 4-16. https://doi.org/10.3991/ ijes.v9i1.19623

[64] Drigas, A., \& Mitsea, E. Skianis Ch. (2021). The Role of Clinical Hypnosis \& VR in Special Education. Int. J. Recent Contributions Eng. Sci. IT. https://doi.org/10.3991/ ijes.v9i4.26147

\section{Authors}

Athanasios Drigas is a Research Director at IIT-N.C.S.R. 'Demokritos', Institute of Informatics and Telecommunications - Net Media Lab \& Mind - Brain R \& D, Agia Paraskevi, 15310, Athens, Greece.

Eleni Mitsea is a Phd Candidate in the Department of Information \& Communication Systems Engineering at the Aegean University in collaboration with the Institute of Informatics and Telecommunications Net Media Lab, Athens, Greece (Email: e.mitsea@gmail.com).

Charalampos Skianis is Vice Rector Finance, Planning \& Development at University of the Aegean and a Professor in the Department of Information and Communication Systems Engineering at the University of the Aegean, Greece (Email: cskianis@aegean.gr).

Article submitted 2021-09-14. Resubmitted 2021-11-14. Final acceptance 2021-11-15. Final version published as submitted by the authors. 